\title{
A Study to Classify the Causes of Stillbirth by Relevant Condition at Death (ReCoDe) in a Tertiary Care Hospital
}

\author{
Sukhvinder Kaur ${ }^{1}$, Md. Aftabuddin Mondal ${ }^{2}$, Anuradha De Pati ${ }^{3}$, Selim Akhtar ${ }^{4}$, Shyamapada Pati ${ }^{5}$, Nidhi Shankar 6 \\ 1, 2, 4, 5, 6 Department of Obstetrics and Gynaecology, Calcutta National Medical \\ College and Hospital, Kolkata, West Bengal, India. ${ }^{3}$ Department of Pathology, \\ Calcutta National Medical College and Hospital, Kolkata, West Bengal, India.
}

\section{ABSTRACT}

\section{BACKGROUND}

Parents and health care workers have to face horrible experiences due to foetal death or stillbirth. Identification of the aetiologies and clinical conditions leading to still births is helpful for reassurance of couples, management of future pregnancies and to reduce its incidence in the society. Over a period of seven years from 1997 - 2003, the new ReCoDe (Relevant Condition at Death) classification system was developed. We performed this study to identify the relevant causes and conditions for foetal death, classify them and to suggest measures to reduce its incidence in general population.

\section{METHODS}

This is a prospective observational study of 120 mothers, done at Department of Obstetrics and Gynaecology of Calcutta National Medical College, Kolkata, from February 2016 to September 2017. Sample size was taken at conveniences.

\section{RESULTS}

Age of the patients ranged between 15 to 40 years. Stillbirths were encountered in $40.83 \%$ of primipara, $21.6 \%$ of $3^{\text {rd }}$ gravida with $2^{\text {nd }}, 4^{\text {th }}$ and $5^{\text {th }}$ gravida $10-15 \%$ each. Maximum stillbirths were observed in 32 - 35 gestational weeks and followed by 36 - 39 weeks gestational age $(37.5 \%$ and $29.16 \%)$ respectively. Out of 120 cases, 68 were boys ( $57 \%$ ), 50 were girls ( $42 \%$ ) and $1.6 \%$ had unidentified sex. Majority of the stillbirth (33\%) were of 1500 - 1999 grams birth weight. Majority of the stillbirths $60 \%$ were fresh and $40 \%$ macerated. 11 cases ( $9 \%$ ) had past history of stillbirths in previous pregnancy. $91 \%$ cases of stillbirths could be assigned a relevant condition as per ReCoDe classification, leaving only $9 \%$ as unclassified or unexplained.

\section{CONCLUSIONS}

Our study simplified the way to classify and identify the relevant causes and conditions of foetal death in our study population. Most patients can be managed properly at right time. Careful antenatal management, proper counselling, early detection of medical disorders in pregnancy with treatment, nutritious diet, timely hospital / doctor visit, social awareness, discouraging superstitions, timely referral to higher facility should be prioritised to reduce the incidence of foetal death.
Corresponding Author: Dr. Selim Akhtar,

Department of Obstetrics and Gynaecology, Neel Diganta, Enclave, Flat - i-3, 3rd Floor, Block-b, Sethpukur, P.O.+ P.S. - Barasat, North 24 Parganas, West Bengal, India. E-mail: s.akhtar19841984@gmail.com

DOI: $10.14260 / \mathrm{jemds} / 2020 / 751$

How to Cite This Article:

Kaur S, Mondal MA, Pati S, et al. A study to classify the causes of stillbirth by relevant condition at death (ReCoDe) in a tertiary care hospital. J Evolution Med Dent Sci 2020;9(46):3422-3426, $10.14260 /$ jemds/2020/751 DOI:

Submission 17-07-2020,

Peer Review 02-10-2020,

Acceptance 08-10-2020,

Published 16-11-2020.

Copyright (C) 2020 Sukhvinder Kaur et al. This is an open access article distributed under Creative Commons Attribution License [Attribution 4.0 International (CC BY 4.0)]

\section{KEY WORDS}

ReCoDe, Stillbirth, Fetal Death, Aetiology. 


\section{BACKGROUND}

Parents and health care workers have to face horrible experiences due to fetal death or stillbirth. The definition of fetal death adopted by the Centres for Disease Control and Prevention National Centre for Health Statistics is as follows: Fetal death means death prior to complete expulsion or extraction from the mother of a product of human conception irrespective of the duration of pregnancy and which is not a induced termination of pregnancy. The death is indicated by the fact that after such expulsion or extraction, the fetus does not breathe or show any other evidence of life such as beating of heart, pulsation of umbilical cord, or definite movement of voluntary muscles. Heartbeats are to be distinguished from transient cardiac contractions; respirations are to be distinguished from fleeting respiratory efforts or grasps. ${ }^{1}$

Identifying specific causes and clinical conditions is important to reduce incidents of stillbirths. Determining causes can be challenging due to complex circumstances of the deaths and relevant investigations are must. The common causes of fetal death are delivery complications, infections \& medical disorders in antenatal period, intra-uterine growth retardation and congenital anomalies. Causes and risk factors depend on income status of different countries and stillbirth rates can be correlated with these differences. But the causes may differ due to their true prevalence as well as different potentialities to evaluate the causes. ${ }^{2}$ Any system to classify death is closely related to its ability to identify the causes of death and the factors which are responsible for the events leading to death.

Over period of seven years from 1997-2003, the new ReCoDe (Relevant Condition at Death) classification system was derived by a study in midlands region. ${ }^{3}$ Fetal growth restriction (43\%) was the most common cause and only 15.2 $\%$ stillbirths remain unexplained by this classification. Several factors (medical and non-medical) influence the evaluation of fetal deaths. First, any single specific cause leading to fetal death is largely not known. Second, causes of previous fetal death are unnoticed due to limited investigation and evaluation. Third, autopsy or other similar procedures are not easy to perform in all events as all families do not agree for that due to different cultures and comfort level.

Two principles seem to be appropriate to consider the most useful tests. First, test must be cost effective to identify a common aetiology. Second, recurrent pregnancy loss should be given more importance than single sporadic event and investigations must be done to evaluate causes of recurrent fetal death. Reassurance and emotional support can be given to a couple by identifying the cause of single sporadic event. Unnecessary tests and interventions in subsequent pregnancies can be avoided by identifying the sporadic cause of stillbirths. ${ }^{4}$ A good clinical evaluation must be emphasised while advising tests and investigations. So, we performed this study to evaluate causes of foetal death and classify it according to ReCoDe classification so that specific measures can be taken to reduce the incidents in our society.

\section{Objectives}

1. To review the causes of stillbirths in a tertiary care centre.
2. To evaluate the characteristics of pregnancies which lead to fetal death as per the classification system-Re Co De (Relevant Condition at Death)

3. To find out the risk factors leading to stillbirth.

4. To identify the measures for early diagnosis and prevention of stillbirth.

\section{METHODS}

Our study was a prospective observational study of 120 mothers which was done at Department of Obstetrics and Gynaecology of Calcutta National Medical College, Kolkata. After getting approval from the Ethical Committee of Calcutta National Medical College, Kolkata in January 2016, we conducted this study from February 2016 to September 2017. Sample size was taken as per convenience.

\section{Inclusion Criteria}

a) Pregnant mothers with intrauterine fetal death at 28 weeks or more gestational period and having birth weight 1000 gm or more.

b) Those fetus died in utero during labour at or above 28 weeks.

\section{Exclusion Criteria}

1. Molar pregnancy

2. Pregnancies less than 28 weeks and birth weight less than $1000 \mathrm{gm}$.

The study included 120 women with intrauterine fetal deaths. These included cases diagnosed in antenatal clinic or those admitted into CNMCH (Calcutta National Medical College and Hospital) directly or referred from outside. Following proper and detailed history taking, a general systemic and obstetric examination and USG confirmation, relevant investigations were done (haemoglobin, ABO-Rh, serum urea, blood sugar, sickling, urine examination, coagulation profile). Thorough examination of umbilical cord and placenta were done after delivery of the dead fetus. Placenta was sent for histopathological examination. Lastly the aetiological factor (s) found for every fetal death was classified as per the ReCoDe classification given by Gardosietal and we counselled the women regarding future conception planning and management.

\section{Statistical Analysis}

The data was entered in Microsoft excel 2013. Percentages were calculated using statistical software STATA version 12 .

\section{RESULTS}

During two-year study a total of 120 women having stillbirth were evaluated in the Obstetrics and Gynaecology Department of Calcutta National Medical College and Hospital. 
The age of the patients ranged between 15 to 40 years. Most of the mothers that is 50 out of 120 (41.6\%) were in the age group of 15 to 20 years. (Table 1 ).

\begin{tabular}{|ccc|}
\hline $\begin{array}{c}\text { Age (in years) of } \\
\text { Mother }\end{array}$ & $\begin{array}{c}\text { Number of Cases } \\
(\mathbf{n = 1 2 0 )}\end{array}$ & Cases in Percentage (\%) \\
$15-20$ & 50 & 41.6 \\
$21-25$ & 32 & 26.6 \\
$26-30$ & 14 & 11.6 \\
$31-35$ & 20 & 16.6 \\
$36-40$ & 4 & 3.3 \\
\hline \multicolumn{3}{|c}{ Table 1. Age Distribution of Cases } \\
\hline
\end{tabular}

In our study, stillbirths were encountered in $40.83 \%$ of primipara, $21.6 \%$ of $3^{\text {rd }}$ gravida with $2^{\text {nd }}, 4^{\text {th }}$ and $5^{\text {th }}$ gravida 10 - $15 \%$ each. (Table 2)

\begin{tabular}{|ccc|}
\hline Parity of Mother & $\begin{array}{c}\text { Number of Cases } \\
(\mathbf{n = 1 2 0})\end{array}$ & Percentage \\
\hline 1 & 49 & 40.83 \\
2 & 15 & 12.5 \\
3 & 26 & 21.6 \\
4 & 17 & 14.16 \\
5 & 13 & 10.83 \\
\hline Table 2. Distribution of Cases According to Parity \\
\hline
\end{tabular}

Maximum stillbirths were observed in 32 - 35 gestational weeks and followed by 36 - 39 weeks gestational age $(37.5 \%$ and $29.16 \%$ ) respectively (Table 3 ).

\begin{tabular}{|ccc|}
\hline $\begin{array}{c}\text { Gestational Age in } \\
\text { Weeks }\end{array}$ & $\begin{array}{c}\text { Number of Cases } \\
(\mathbf{n = 1 2 0})\end{array}$ & Percentage (\%) \\
$28-31$ & 22 & 18.33 \\
$32-35$ & 45 & 37.5 \\
$36-39$ & 35 & 29.16 \\
40 and above & 18 & 15 \\
\hline Table 3. Distribution of Cases According to Gestational Age in Weeks \\
\hline
\end{tabular}

We also found that out of 120 cases, 68 were boys (57\%) and 50 were girls (42\%) and $1.6 \%$ had unidentified sex (amorphous fetus). Majority of the stillbirth (33\%) were of 1500-1999 grams birth weight. Majority of the stillbirth $60 \%$ were fresh and $40 \%$ macerated. Aetiologies of fresh and macerated stillbirths are classified in Table 4.

\begin{tabular}{|ccc|}
\hline Aetiology of Stillbirth & $\begin{array}{c}\text { Fresh } \\
\text { Stillborn }\end{array}$ & $\begin{array}{c}\text { Macerated } \\
\text { Stillborn }\end{array}$ \\
Lethal congenital anomaly & 3 & 5 \\
Fetal infection & - & 1 \\
Non immune hydrops & 1 & - \\
Twin-twin transfusion syndrome & 1 & - \\
Fetal growth restriction & 12 & 5 \\
Cord prolapse & 3 & - \\
Constricting umbilical cord loop or knot & 2 & - \\
Abruptio placentae & 4 & 6 \\
Placenta praevia & 2 & 1 \\
Oligohydramnios & 5 & 5 \\
Polyhydramnios & 1 & - \\
Ruptured uterus & 2 & 3 \\
Obstructed labour & 2 & 2 \\
Diabetes mellitus & - & 2 \\
Essential hypertension & 1 & 1 \\
Hypertensive disorders in pregnancy & 18 & 10 \\
Antiphospholipid antibody syndrome & 1 & - \\
Cholestasis & 4 & - \\
Heart disease, anaemia, others & 3 & - \\
\hline Birth asphyxia & 4 & - \\
No relevant condition identified & 3 & 7 \\
No information available & - & - \\
Total & $\mathbf{4 2}$ \\
\hline Table 4. Classification of Fresh and Macerated Stillbirths \\
According to Aetiology & \\
\hline
\end{tabular}

In our study 11 cases ( $9 \%$ ) had history of fetal death in previous pregnancy. Of these 11 cases 4 cases had pregnancy induced hypertension in previous pregnancy, 2 of them had congenital abnormality and 1 case had Anti-Phospholipid Antibodies Syndrome (APLA) and 4 cases had no cause.

We found 40 positive histopathological findings of placenta out of 95 placentae sent for histopathological examination.

Thickened arteries and veins, perivascular fibrosis seen with areas of necrosis and haemorrhage and decidual fibrin deposition suggestive of hypertensive disorder in 18 placentas.

Intrachorionic and retroplacental haemorrhage with perivillous fibrin deposition suggestive of placental abruption found in 09 placentas.

Placenta with increased syncytial knots, intervillous fibrosis, intravillous and perivillous fibrin deposition suggestive of fetal growth restriction found in 13 placentas.

\begin{tabular}{|c|c|c|c|c|}
\hline Groups & $\begin{array}{c}\text { Total } \\
\text { Percentage }\end{array}$ & Causes of Stillbirths & $\begin{array}{l}\text { No. of } \\
\text { Cases }\end{array}$ & $\%$ \\
\hline \multirow{7}{*}{ A-fetus } & $23.3 \%$ & A1 Lethal congenital anomaly & 8 & $6.6 \%$ \\
\hline & & A2 Infections & 1 & $0.8 \%$ \\
\hline & & A3 Non immune hydrops & 1 & $0.8 \%$ \\
\hline & & A4 Isoimmunisation & 0 & 0 \\
\hline & & A5 Feto-maternal haemorrhage & 0 & 0 \\
\hline & & A6 Twin-twin transfusion syndrome & 1 & $0.8 \%$ \\
\hline & & A7 Fetal growth restriction & 17 & $14.1 \%$ \\
\hline \multirow[t]{3}{*}{$\begin{array}{l}\text { B-Umbilical } \\
\text { cord }\end{array}$} & $4.16 \%$ & B1 Cord prolapse & 3 & $2.5 \%$ \\
\hline & & $\begin{array}{l}\text { B2 Constricting umbilical cord loop } \\
\text { or knot }\end{array}$ & 2 & $1.6 \%$ \\
\hline & & B3 Velamentous insertion & 0 & 0 \\
\hline \multirow{3}{*}{ C-Placenta } & $10.83 \%$ & C1 Abruptio placentae & 10 & $8.3 \%$ \\
\hline & & C2 Placenta praevia & 3 & $2.5 \%$ \\
\hline & & C3 Vasa praevia & 0 & 0 \\
\hline \multirow[t]{3}{*}{$\begin{array}{l}\text { D-Amniotic } \\
\text { fluid }\end{array}$} & $9.16 \%$ & D1 Chorioamnionitis & 0 & 0 \\
\hline & & D2 Oligohydramnios & 10 & $8.3 \%$ \\
\hline & & D3 Polyhydramnios & 1 & $0.8 \%$ \\
\hline \multirow[t]{3}{*}{ E-Uterus } & $7.5 \%$ & E1 Rupture uterus & 5 & $4.16 \%$ \\
\hline & & E2 Uterine anomaly & 0 & 0 \\
\hline & & E3 Obstructed labour & 4 & $3.3 \%$ \\
\hline \multirow[t]{9}{*}{ F- Mother } & $33.33 \%$ & F1 Diabetes mellitus & 2 & $1.6 \%$ \\
\hline & & F2 Thyroid disorder & 0 & 0 \\
\hline & & F3 Essential hypertension & 2 & $1.6 \%$ \\
\hline & & $\begin{array}{l}\text { F4 Hypertensive disorders in } \\
\text { pregnancy }\end{array}$ & 28 & $23.3 \%$ \\
\hline & & $\begin{array}{l}\text { F5 Antiphospholipid antibody } \\
\text { syndrome }\end{array}$ & 1 & $0.8 \%$ \\
\hline & & F6 Cholestasis & 4 & $3.3 \%$ \\
\hline & & F7 Drug misuse & 0 & 0 \\
\hline & & F8 Infection & 0 & 0 \\
\hline & & F9 Other anaemia heart disease & 3 & $2.5 \%$ \\
\hline \multirow{2}{*}{$\begin{array}{c}\text { G- } \\
\text { Intrapartum }\end{array}$} & $3.33 \%$ & G1 Birth asphyxia & 4 & $3.3 \%$ \\
\hline & & G2 Birth trauma & 0 & 0 \\
\hline \multirow[t]{2}{*}{ H- Trauma } & 0 & H1 External & 0 & 0 \\
\hline & & H2 Iatrogenic & 0 & 0 \\
\hline \multirow[t]{2}{*}{$\begin{array}{c}\text { I- } \\
\text { Unclassified }\end{array}$} & $9.16 \%$ & $\begin{array}{l}\text { I1 relevant condition could not be } \\
\text { identified }\end{array}$ & 10 & $8.3 \%$ \\
\hline & & I2 information not available & - & - \\
\hline Total & & & 120 & \\
\hline & Ac & $\begin{array}{l}\text { ary of Aetiological Factors for } \\
\text { ding to ReCoDe Classification }\end{array}$ & illbir & \\
\hline
\end{tabular}

As it is clear from Table $V$ that most of the fetal deaths were falling into various classes of ReCoDe classification this suggests multifactorial cause of death of fetus.

\section{DISCUSSION}

The analysis of stillbirths occurring over a period of one and half year according to the ReCoDe classification showed that $91 \%$ cases of stillbirths could be classified for relevant causes, only $9 \%$ could not be classified or remained unexplained. During our study period there were total of 11565 births out of which 381 were stillborn. A total of 120 cases of stillbirth 
were studied that fulfilled the inclusion criteria. Out of these 120 cases only for 11 cases no relevant condition was identified.

In our study stillbirth rate was high in the age group 15 25 years $(67 \%)$ which was similar to Balu et al from India. ${ }^{5}$ However in certain other studies 6,7 the authors have pointed out the advanced maternal age as an adverse factor for increases in stillbirth rate, but our hospital had most pregnant women referred from rural background where women get married early and conceived soon.

In our study, maximum fetal deaths are seen in primipara (40\%) similar to the study by researchers in a tertiary hospital from Bhavnagar, India, ${ }^{8} 37 \%$ of stillbirths in our study were seen in 32 - 35 weeks of gestational age and $31 \%$ in 36 - 39 weeks of gestational age. Our findings confirm to the observation of the study in which the author ${ }^{9}$ noted $67 \%$ stillbirth in less than 36 weeks of pregnancy.

In present study out of 120 cases 68 of stillborn babies were boy i.e. $56.6 \%$ indicating that boys have less resistance to withstand the adverse environment due to their genetic makeup. Birth weight is one of the important factors for unfavourable outcome. Birth weight of dead fetus ranging from $1 \mathrm{~kg}$ to $1.5 \mathrm{~kg}$, our stillbirth rate was $29 \%$. In case of birth weight $>2.5 \mathrm{~kg}$, it was $12 \%$ in this study group. Savvas et al ${ }^{10}$ also found a noticeable relationship between fetal death and small for gestational age. As per their study, $50 \%$ of the still born were less than 10 percentile for weight. Ajini et al ${ }^{11}$ also had similar findings.

In the present study $9 \%$ had past history of stillbirths. Bhattacharya et al ${ }^{12}$ showed that when confounding factors are adjusted, the odds of recurrence of fetal deaths in a second pregnancy was 1.94 compared with those mothers who had a live birth in the first pregnancy. Sharma et al ${ }^{13}$ observed a fivefold increased risk of recurrence of stillbirth in subsequent pregnancies.

Stillbirth can be categorized as antepartum and intrapartum. In this study $68 \%$ of stillborn babies were fresh indicating the importance of intranatal care. Fresh stillbirths indicates the intrapartum management quality and macerated stillbirths indicates antenatal period management quality and care. In developed countries the incidence of intrapartum stillbirth indicates inadequate care and management. In developing countries it may indicate inability to access for essential maternal care and inadequate management.

In this study, the maternal causes of stillbirths formed 33.3 $\%$ of all stillbirths. While considering the aetiology in the group of maternal factors subgroup F4-hypertensive disorders of pregnancy has constituted $23.3 \%$. Fetal death or major neonatal morbidity were more likely to occur in mother having hypertension in pregnancy than normotensive pregnant women.

Among the fetal causes (23.3\%), fetal growth restriction forms the largest sub group (14.1\%) and then lethal congenital anomaly ( $6.6 \%$ ) though Gardosi et $\mathrm{al}^{3}$ found fetal causes of stillbirths in $64.3 \%$ cases, with maximum numbers among being attributed to fetal growth restriction (43\%) and lethal congenital anomaly (14.95\%) like anencephaly, spina bifida and one case with multiple congenital anomalies like anophthalmia, omphalocele, polydactyly etc. clinically matching with the features of Patau syndrome which were incompatible with life.
In the present study, group C placental causes formed 10.3 $\%$ of all stillbirths, consisting of abruptio placenta (8.5\%) and placenta previa (2.3\%).

Amniotic fluid as an aetiological factor constituted $9 \%$ of all stillbirths, consisting of oligohydramnios (8\%) and polyhydramnios $(1 \%)$ in our study. Yagnik et al India ${ }^{8}$ reported $20 \%$ of cases in this group in their study.

Group E - The uterine factors are also one of the significant factors for an adverse fetal outcome contributing $7.5 \%$ of stillbirths. This is comparable to study conducted by Sing et $\mathrm{al}^{14}$ in which uterine causes formed $8.6 \%$ of all stillbirths.

\section{CONCLUSIONS}

Most of the present systems which classify foetal death either depend on lots of costly investigations or as per their classification major portion of the stillbirths remain unexplained. ReCoDe system is suitable for India and other developing countries as in this system, minimum investigations are performed. We noticed unexplained foetal deaths in $9 \%$ cases only.

Thus, our study simplified the way to classify and find the way to identify the relevant causes and conditions at foetal death in our study population. Our study indicates that most of the conditions can be managed properly at the right time.

Careful antenatal management, proper counselling, early detection of medical disorders in pregnancy with treatment, nutritious diet, timely hospital / doctor visit, social awareness, discouraging superstitions, timely referral to higher facilities can be given importance and priority to reduce incidents of incidents of foetal death.

Hospitals should have still birth audits for identifying the relevant causes and conditions so that these can be taken care of and prevented.

Classifying stillbirths will provide them opportunity for recognizing the requirement for close monitoring of mothers in future. Determining the cause of stillbirth aids maternal psychological adaptation to a significant loss, permits more accurate counselling regarding recurrence risk and timely treatment or management for prevention of similar incidence in future pregnancy. Inherited disease identification is also useful and informative for other family members.

Data sharing statement provided by the authors is available with the full text of this article at jemds.com.

Financial or other competing interests: None.

Disclosure forms provided by the authors are available with the full text of this article at jemds.com.

\section{REFERENCES}

[1] MacDorman MF, Kirmeyer SE, Wilson EC. Fetal and perinatal mortality, United States 2006. Natl Vital Stat Rep 2012:60(8):1-22.

[2] Smith GC, Crossley JA, Aitken DA, et al. First-trimester placentation and the risk of antepartum stillbirth. JAMA 2004;292(18):2249-54.

[3] Gardosi J, Kady SM, McGeown P, et al. Classification of stillbirth by relevant condition at death (ReCoDe): 
population based cohort study. BMJ 2005;331(7525):1113-7.

[4] Silver RM, Verner MW, Reddy U, et al. Work-up of stillbirths: a review of the evidence. Am J Obstet Gynaecol 2007;196(5):433-44.

[5] Divya B, Aswini NU, Asha SOV. A study of intrauterine fetal death in a tertiary care hospital. Int J Reprod Contracept Obstet Gynecol 2015;4(6):2028-31.

[6] Parihar BC, Goyal A. A study to evaluate the causes of stillbirths according to the ReCoDe classification. Int J Reprod Contracept Obstet Gynecol 2017;6(4):1288-94.

[7] Singh A, Alpana T. Re. Co. De.: a better classification for determination of still births. J Obstetr Gynaecol India 2011;61:656-8.

[8] Ami Y, Gokhle AV. Study of cases of still births at tertiary maternity care hospital (ReCoDe). Int J Med Res Health Sci 2016;5(6):102-21.

[9] Rajagopal VM, Betha K, Priya GS. Classification of stillbirth by relative condition at death ( $\mathrm{Re}$ Co De) at various trimesters of pregnancy: a rural tertiary teaching hospital based study. Int J Reprod Contracept Obstet Gynecol 2017;6(8):3550-5.

[10] Efkarpidis E, Alexopoulos E, Kean L, et al. Case control study of factors associated with intrauterine foetal deaths. Med Gen Med 2004;6(2):53.

[11] Ajini KK, Radha KR, Reena RP. Classification of stillbirths by relevant condition at death (ReCoDe): a cross sectional study at a rural tertiary care centre in Kerala, India. Int J Reprod Contracept Obstet Gynecol 2017;6(3):1061-6.

[12] Bhattacharya S, Prescott GJ, Black M, et al. Recurrence risk of stillbirth in a second pregnancy. BJOG 2010;117(10):1243-7.

[13] Sharma PP, Salihu HM, Oyelese Y, et al. Is race a determinant of stillbirth recurrence? Obstet Gynecol 2006;107(2 Pt 1):391-7.

[14] Singh A, Alpana T. Re.Co. De.: a better classification for determination of still births. J Obstet Gynaecol India 2011;61(6):656-8. 